\title{
Second-generation uncemented stems: excellent 5-13-year results
}

\author{
Moritz Tannast $\cdot$ Timo M. Ecker $\cdot$ Stephen B. Murphy
}

Received: 13 November 2008 / Published online: 17 October 2009

(C) Springer-Verlag 2009

\begin{abstract}
Introduction The purpose of this study was to prospectively evaluate the 5-13-year results of a cementless total hip arthroplasty with a special focus on the survivorship, occurrence of osteolysis, incidence of intraoperative femoral fractures, thigh pain, and cortical hypertrophy of the femoral stem. The femoral component used in this study was titanium fluted, slotted, symmetrical component that was prepared with intraoperative machining. The proximal third of the stem had hydroxyl-apatite coating and horizontal steps.

Methods The clinical and radiographical results of a consecutive series of 157 total hip arthroplasties (124 patients) with this stem were investigated. Minimum follow-up was 5 years. The average age of the patients at the time of surgery was 47 years. Three patients died and ten patients were lost to follow-up, leaving 142 hips for evaluation. The clinical result was evaluated on the basis of the Merle d'Aubigné score, complications and thigh pain. A detailed radiographic analysis was performed at each follow-up visit. Kaplan-Meier survivorship analysis was performed to evaluate stem, cup, and bearing survivorship.

Results The mean follow-up was 8.5 years (range 5-13 years). The average Merle d'Aubigné score improved from
\end{abstract}

Electronic supplementary material The online version of this article (doi:10.1007/s00402-009-0977-7) contains supplementary material, which is available to authorized users.

M. Tannast · T. M. Ecker · S. B. Murphy

Center for Computer Assisted and Reconstructive Surgery,

New England Baptist Hospital,

Tufts University School of Medicine, Boston, MA, USA

M. Tannast $(\bowtie) \cdot$ T. M. Ecker

Department of Orthopaedic Surgery, Inselspital,

University of Bern, Murtenstrasse, 3010 Bern, Switzerland

e-mail: moritz.tannast@insel.ch
10.5 points preoperatively to 17.4 points postoperatively. The cumulative 10 -year survival rate was $99 \%$ for the femoral component, $99 \%$ for the acetabular component, and $69 \%$ for the bearing. Thigh pain was identified in three patients (2\%). There was no distal femoral osteolysis. Seventy-nine percent of all the hips had endosteal spot welds around the coated, proximal one-third of the prosthesis. $51 \%$ had radiodense lines around the distal tip of the prosthesis, and 3\% had cortical hypertrophy. One undersized stem and one cup were revised for aseptic loosening, and 25 bearings were exchanged.

Conclusions Uncemented, machined, fluted titanium canal-filling femoral components achieve reliable fixation in this young patient population. They have a decreased incidence of activity-related thigh pain, lower rate of intraoperative femur fractures and cortical hypertrophy with comparable bone-ingrowth in comparison to other secondgeneration uncemented femoral components described in literature. Bearing wear and the need for bearing exchange was the only limitation of these constructs.

Keywords Total hip arthroplasty · Cementless .

Stem $\cdot$ Long-term results

$\begin{array}{ll}\text { Abbreviation } \\ \text { THA } & \text { Total hip arthroplasty } \\ \text { HA } & \text { Hydroxyl-apatite } \\ \text { PE } & \text { Polyethylene }\end{array}$

\section{Introduction}

Cementless fixation techniques in total hip arthroplasty (THA) are increasingly used worldwide, particularly in younger and more active patients [1, 19, 41]. Uncemented 
femoral components were designed to decrease failure rates due to aseptic loosening, which were found to be the most common long-term complication of cemented stems $[2$, 24]. However, first generation of cementless femoral components fell short of expectations because they were associated with intraoperative femoral fractures, high incidence of postoperative thigh pain, stress shielding, subsidence, early loosening, and endosteolysis $[4-6,11,14,15$, 21, 29, 32, 37, 47].

Based on these early experiences, an intraoperatively machined, proximally load bearing, coronally slotted, hydroxyl-apatite (HA)-coated titanium stem with horizontal metaphyseal steps was developed to address these problems. The HA coating is covering the stepped surface of the proximal sleeve. The combination of coating and textured surface is engineered to provide optimized fit and to enhance more natural compressive load bearing.

Preliminary results of an initial series of the first 64 operations with this stem were published in a previous report [40]. In contrast to other reports of so-called 'second-generation' stems impacted with a broach-only technique, no intraoperative femur fractures occurred. No cases of activity-related thigh pain were observed at 1 year, and all stems osseointegrated fully without signs of osteolysis in the distal part of the stem.

The purpose of this prospective study was to assess 10 -year implant survival rates, clinical outcomes, and radiographic results in a consecutive series of patients treated with this second-generation stem. First, we hypothesized that the new design of the stem leads to a higher long-term survival rate in comparison to first-generation stems and to a comparable survivorship with other second-generation stems. The second hypothesis was that this particular stem has a decreased incidence of activity-related thigh pain, lower rate of intraoperative femur fractures and cortical hypertrophy with comparable bone-ingrowth in comparison to other second-generation uncemented femoral components described in the literature.

\section{Materials and methods}

\section{Patient demographics}

We prospectively followed 157 consecutive primary total hip arthroplasties with a second-generation cementless stem in 124 patients with a special focus on intraoperative complications, long-term clinical outcome with survivorship, and radiographic analysis. The results were compared with the results of other first- and second-generation cementless femoral components described in literature.

All procedures were performed by the senior author (SBM) between July 1992 and October 1999. The study group included 59 men and 65 women. The average age (and SD) of the patients at the time of surgery was $46.9 \pm 10.5$ years (range 22.9-70.1). The mean height was $170 \pm 9 \mathrm{~cm}$ (range 145-195), the mean weight was $82 \pm 20 \mathrm{~kg}$ (range 45-134), and the mean body mass index was $27.9 \pm 5.5 \mathrm{~kg} \mathrm{~m}^{-2}$ (range 18.3-41.2). Eighty-three right hips and 74 left hips were involved. The preoperative diagnoses were typical for this age range (Table 1). Thirtyeight of the 157 hips (24\%) had previous surgery (Table 2).

Operative technique

Total hip arthroplasty was performed through a modified direct lateral approach in 150 hips $(95.5 \%)$, through a trochanteric slide exposure in 6 hips (3.8\%) and through a vastus slide exposure in 1 patient $(0.6 \%)$. The modified direct lateral approach is basically a classical transgluteal approach in lateral decubitus position. The modification consisted of the elevation of an additional thin bony wafer of the anterior part of the greater trochanter. The trochanteric slide exposure consists of a trochanteric osteotomy where the vastus lateralis fascia distally and the $\mathrm{Mm}$. gluteus medius and minimus proximally are connected to the

Table 1 Preoperative diagnosis of the 157 hips included in the study

\begin{tabular}{ll}
\hline Underlying disease & $\begin{array}{l}\text { Number of } \\
\text { hips (\%) }\end{array}$ \\
\hline Osteoarthritis & $60(38)$ \\
Dysplasia & $53(34)$ \\
Avascular necrosis & $14(9)$ \\
Posttraumatic osteoarthritis & $10(6)$ \\
Slipped capital femoral epiphysis & $5(3)$ \\
Legg-Calvé-Perthes disease & $5(3)$ \\
Cerebral palsy & $3(2)$ \\
Spondyloarthropathy & $2(1)$ \\
Rheumatoid arthritis & $2(1)$ \\
Other & $3(2)$ \\
\hline
\end{tabular}

Table 2 Details of the 38 patients with previous surgical interventions

\begin{tabular}{ll}
\hline Previous surgical intervention & Hips $(n)$ \\
\hline Pelvic and/or femoral osteotomies & 17 \\
Open reduction and internal fixation & 5 \\
Hemiarthroplasties & 3 \\
Fibular allografts & 3 \\
Surgical hip dislocations & 2 \\
Arthroscopies & 2 \\
Excisions (synovial cyst, osteochondroma) & 2 \\
Pinning slipped capital femoral epiphysis & 1 \\
Arthrotomy & 1 \\
Multiple femoral/pelvic surgeries in childhood & 2
\end{tabular}


trochanteric osteotomy. The vastus slide approach is a transgluteal exposure above the vastus tubercle and it becomes a lateral exposure of the femur below the vastus tubercle without trochanteric osteotomy. The quadriceps is then connected to the anterior part of the transgluteal approach.

The femoral component consisted of titanium, cylindrical, symmetric, slotted, fluted design with proximal HA coating $(50 \mu \mathrm{m})$ (Stability femoral component, DePuy Orthopaedics, AJ\&J Company, Warsaw, IN, USA) [40]. The stem is a further development of the S-ROM concept. It is prepared using a cylindrical diaphyseal reamer, a conical metaphyseal reamer, an angled drill for preparation of the calcar region, and a final broach.

The acetabular component consisted of a spherical titanium shell with porous coating of two manufacturers (Duraloc, DePuy, A J\&J Company, Warsaw, IN, USA). 143 acetabular components had no screw holes (100 series), 11 had up to 3 screw holes (6 Bantam series, 5 Sector series), and 3 had 8-12 screw holes (1200 series). A polyethylene (PE) bearing surface was used for all hips. Early in the series, a Hylamer PE liner was used in 36 hips prior to December 1994; thereafter, an Enduron PE was implanted in 103. Beginning in December 1998, a highly cross-linked PE Marathon liner was implanted in 18 hips. Seventy-one hips had a Zirconia ceramic femoral head, 57 had an Alumina ceramic femoral head and 29 hips a cobalt-chrome femoral head. Implant information is summarized in Table 3.

Follow-up evaluation

Three patients ( 3 hips, 2\%) had died from unrelated causes $2.1,2.5$ and 5.3 years postoperatively. Ten patients $(12$ hips, $8 \%$ ) were lost to follow-up. Thus, the status of 142 of the original 157 hips (111 patients, 90\%) was known at the last follow-up examination. The mean duration of followup was 8.5 years (range 5-13 years). Ninety-five patients (124 hips, 87\%) were evaluated both clinically and radiographically. The remaining 16 patients (18 hips) were unable to return for a clinical evaluation for reasons not related to the result of the arthroplasty, and they were evaluated on the basis of a telephone interview only. In this interview, patients were asked predefined questions from a questionnaire described later to asses their hip function.

Patients were assessed preoperatively; at 6 and 12 weeks; and annually thereafter, if possible. The minimal follow-up was set at 5 years. At each visit, patients were asked to fill out a standardized and validated hip questionnaire $[25,28]$ including information about severity and location of pain, especially emphasizing occurrence of thigh pain, and their functional status. All the patients were clinically examined by the operating surgeon. Those who were unable to return were interviewed by telephone and
Table 3 Implant information

\begin{tabular}{|c|c|}
\hline Implant information & Number used \\
\hline \multicolumn{2}{|l|}{ Head size } \\
\hline 22 & 9 \\
\hline 26 & 46 \\
\hline 28 & 100 \\
\hline 32 & 2 \\
\hline \multicolumn{2}{|l|}{ Cup size } \\
\hline 44 & 1 \\
\hline 46 & 3 \\
\hline 48 & 12 \\
\hline 50 & 11 \\
\hline 52 & 32 \\
\hline 54 & 35 \\
\hline 56 & 36 \\
\hline 58 & 23 \\
\hline 60 & 2 \\
\hline 62 & 2 \\
\hline \multicolumn{2}{|l|}{ Head material } \\
\hline Cobalt-chrome & 29 \\
\hline Ceramic (Zirconia) & 71 \\
\hline Ceramic (Alumina) & 57 \\
\hline \multicolumn{2}{|l|}{ Liners } \\
\hline Hylamer PE & 36 \\
\hline Enduron PE & 103 \\
\hline Cross-linked Marathon PE & 18 \\
\hline
\end{tabular}

Total number $n=157$

$P E$ polyethylene

asked to have radiographs taken locally and then sent to us. Members of the families of the patients who had died were interviewed to determine the function of the hip at the time of death. Clinical outcome was rated according to the Merle d'Aubigné Score [38]. Clinical results were then classified as excellent (18 points), very good (17 points), good (16 points), fair (15 points), and poor (14 points or less). All complications related to the hip arthroplasty were reported and divided into three categories (intraoperative, perioperative, and postoperative).

Radiographic evaluation

Serial anteroposterior, lateral, and false profile radiographs of the pelvis were analyzed by a second independent observer (MT) who was blinded to the clinical outcome of the corresponding patients. Prosthetic component orientation was measured with the use of a caliper for which a mean reliability and reproducibility of $<1^{\circ}$ for the acetabular component and could be found [26]. Because cup version cannot be reliably measured on anteroposterior pelvic radiographs, only cup abduction was measured with the 
inter teardrop line as a horizontal reference [45]. Stem position (varus, valgus, or neutral alignment) was established as the angle formed by the intersection of a line drawn through the longitudinal axis of the proximal part of the femoral canal and a line drawn through the longitudinal axis of the stem [34].

The locations of the radiographic findings of the femur were recorded using of the Gruen zones (Fig. 1) and of the acetabulum using the DeLee and Charnley zones [12, 18]. The following standard set of radiographic parameters was assessed: femoral cancellous densification (so-called endosteal spots) was identified by a qualitative increase in bone density anywhere between the implant and the femoral cortex [15]. Radiodense lines were indicated by a thin radiopaque layer of bone seen parallel, and in close proximity to the implant and covering at least $50 \%$ of the zone length [8]. Cortical hypertrophy was defined as an increase in the outer diameter of the cortex [23, 34]. Radiolucency was defined as a radiolucent zone anywhere around the implant at least 2-mm-wide, and covering at least $30 \%$ of any zone [23]. Calcar re-modeling was classified as hypertrophy if there was a densification of the proximal femoral osteotomy side and as atrophy if there was a visible loss of trabecular bone density [22]. Heterotopic ossifications were graded with the Brooker classification [7]. Vertical subsidence was defined as a minimum $5 \mathrm{~mm}$ change of the distance from the superolateral edge of the stem to the tip of the greater trochanter between the immediately postoperative and the latest anteroposterior radiograph [44]. Osteolysis was defined as bone resorption, with a visible loss of trabecular bone density or cortical thinning. Peritrochanteric osteolysis was defined as osteolysis in the greater trochanteric region cranial to zone 1. Retroacetabular osteolysis was judged on the false profile view. Because it
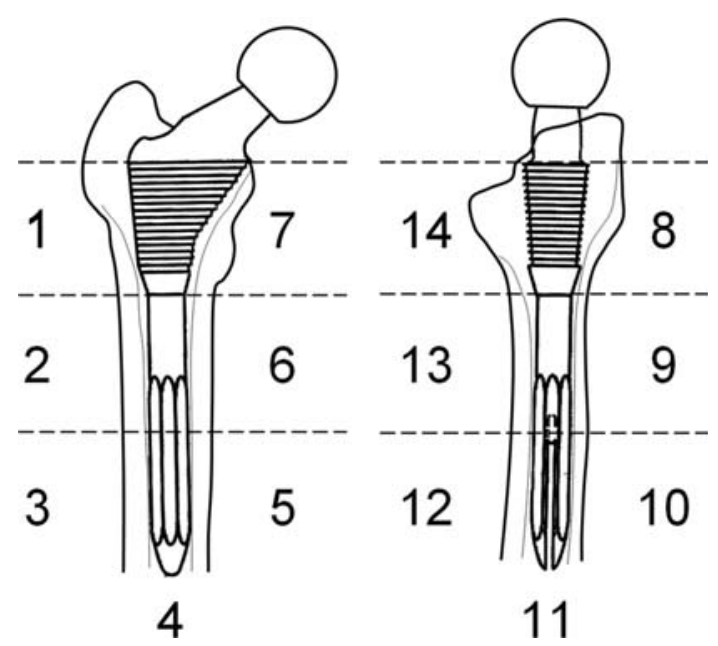

Fig. 1 The radiographic zones for the investigated stem according to Gruen are shown [18] could be shown that the radiographic interpretation of femoral components can be made with substantial reliability and reproducibility [31], no such analysis was performed.

\section{Statistical analysis}

Kaplan-Meier survivorship analysis was performed to determine the cumulative survival rate for the each component with revision for each component as the end point [27]. Normal distribution was determined with the Kolmogorov-Smirnov test. Paired and unpaired student's $t$ tests were used for comparison of normally distributed data. The Wilcoxon rank sum and the Mann-Whitney $U$ tests were used when comparing paired and non-paired data without normal distribution. To assess associations between categorical variables, Fisher's exact test was performed. Significance was defined as a $p$ value of $<0.05$.

\section{Results}

\section{Clinical evaluation}

Merle d'Aubigné score of the 115 non-revised hips improved from 10.5 preoperatively (range 5-14) to 17.4 (range 12-18) at the 5-12-year follow-up (Table 4, $p<0.0001)$. Among the seven patients with a poor result, three patients had persistent pain (one of them with Grade 3 heterotopic ossification), one patient had deficit in the range of motion and three other patients needed walking support at the time of latest follow-up.

Four of the 137 non-stem-revised hips (2.9\%) were related with thigh pain. Two patients had mild thigh pain that occurred predominantly with prolonged activity and which required medication occasionally. One patient had moderate and another severe pain that occurred with all activities and required regular pain medication. None of these three patients had clinical or radiographic signs of stem loosening. We did not observe a specific time-dependent pattern for the occurrence of thigh pain.

\section{Complications}

Among the eight major complications (Table 5), there were one intraoperative, two perioperative, and five postoperative complications without a case of intraoperative femur fracture, deep infection, nerve palsy, or diagnosis of deep venous thrombosis. One of the postoperative dislocations occurred 4.7 years postoperatively and underwent closed reduction without further intervention. The other patient with postoperative dislocation, who had postoperatively lost $45 \mathrm{~kg}$ of weight after gastric bypass, sustained four dislocations beginning 35 months after surgery. This patient 
Table 4 Summary of the clinical and radiographical results

\begin{tabular}{ll}
\hline Parameter & Number $(\%)$ \\
\hline Postoperative Merle d'Aubigné score & \\
Excellent (\%) & $79(69)$ \\
Very good (\%) & $22(19)$ \\
Good (\%) & $4(3)$ \\
Fair $(\%)$ & $3(3)$ \\
Poor (\%) & $7(6)$ \\
Number of hips with thigh pain $(\%)$ & $4(2.9)$ \\
Mean cup abduction & $41.5^{\circ} \pm 6.4^{\circ}(28-64)$ \\
Stem alignment & \\
Neutral & $105(83)$ \\
Varus & $7(6)$ \\
Valgus & $13(10)$ \\
New cortical hypertrophy & $3(2)$ \\
Subsidence $>5$ mm & $1(1)$ \\
Heterotopic ossifications & \\
Grade 0 & $94(76)$ \\
Grade 1 & $20(16)$ \\
Grade 2 & $3(2)$ \\
Grade 3 & $7(6)$ \\
Grade 4 & $0(0)$ \\
Calcar reaction & 1 \\
No changes (\%) & $103(82)$ \\
Atrophy (\%) & $16(13)$ \\
Hypertrophy (\%) & $5(4)$ \\
Peritrochanteric osteolysis & $25(20)$ \\
Retroacetabular osteolysis & $16(13)$ \\
&
\end{tabular}

Table 5 List of complications

\begin{tabular}{ll}
\hline Category & Number \\
\hline Intraoperative & 1 \\
$\quad$ Iliac vein laceration & \\
Perioperative & 1 \\
$\quad$ Superficial wound infection & 1 \\
$\quad$ Seizure due to bupivacaine toxicity & \\
Postoperative & 2 \\
Dislocations & 2 \\
Greater trochanteric fracture & 1 \\
Periprosthetic fracture & \\
\hline
\end{tabular}

required revision with a lipped liner 4.1 years after initial surgery and had remained stable. Among the two patients with postoperative greater trochanteric fractures, one occurred in the postoperative rehabilitation requiring internal fixation 3 weeks after the initial surgery. The second was an incomplete fracture of the greater trochanter after fall 1.9 years postoperatively and was successfully treated conservatively. One patient had a periprosthetic diaphyseal fracture after trauma 9.2 years after THA and underwent internal fixation. The fracture healed uneventfully without revision of the femoral component.

Radiographic results

A characteristic pattern of bone-ingrowth of the femoral component was seen (Tables 6, 7); with 107 of the hips $(86 \%)$ having endosteal spot welds in Gruen zones 1, 7 , or 8 . These circumscribed areas of stress transfer are typically located at the junction between the conical and the straight portion of the femoral component. Sixtythree hips (51\%) had radiodense lines around the distal tip of the prosthesis (zones $3-5$ or 10-12). There was no endosteolysis in any of the diaphyseal zones (zones 2-6, or zones 9-13). Radiolucent lines in zone 1 were only located around the stem shoulder and did not continue to the distal part of this zone. Cups with one single dome hole demonstrated lysis only in zone II. The incidence of femoral cortical hypertrophy was $6 \%$ (8 hips). Five of the eight patients had previous femoral osteotomies with preexisting hypertrophic changes. Two femurs with correct alignment showed isolated hypertrophy in zones 5 and 2 , respectively. One femur in varus orientation showed isolated hypertrophy in zone 5 .

\section{Revisions}

There were 1 stem revision, 1 metal shell revision and 25 exchanges of the PE bearing. The bearing exchanges (15 Hylamer, 10 Enduron PE liners) were performed for polyethylene wear associated with progressive retroacetabular or peritrochanteric osteolysis. The number of bearing exchanges was significantly higher for the Hylamer PE liners (Table 8). One hip had a combined revision of the liner and the loosened metal shell. This hip had a broken locking mechanism and part of the broken locking ring migrated into the articulation. There was resulting wear and the cup was found to be loose at surgery. Mean time to revision was $7.9 \pm 2.3$ years (range 2.2-12.5). In all, 25 hips that had a revision of the acetabular component (polyethylene liner and metal shell), the stem was clinically, radiographically and intraoperatively fully stable. Revision of the polyethylene liner was correlated with increased head diameter, but not with younger age, abduction outliers, sex, side, height, weight, body mass index, stem alignment, cup diameter, or previous operations (Table 8).

One patient had an undersized femoral component that failed to osseointegrate. He had a painless fibrous interface, which became painful more than 2 years after the surgery and was revised 3.1 years postoperatively. 
Table 6 Radiographic findings on the anteroposterior radiographs of 123 of the non-revised femora

\begin{tabular}{|c|c|c|c|c|c|c|c|c|c|c|c|c|c|c|}
\hline \multirow[t]{2}{*}{ Parameter } & \multicolumn{14}{|c|}{ Number of hips (\%) } \\
\hline & Zone 1 & Zone 2 & Zone 3 & Zone 4 & Zone 5 & Zone 6 & Zone 7 & Zone 8 & Zone 9 & Zone 10 & Zone 1 & Zone 1 & Zone & Zon \\
\hline Radiolucent lines & $17(14)$ & $0(0)$ & $0(0)$ & $0(0)$ & $0(0)$ & $0(0)$ & $2(2)$ & $7(6)$ & $0(0)$ & $0(0)$ & $0(0)$ & $0(0)$ & $0(0)$ & $0(0)$ \\
\hline Radiodense lines & $0(0)$ & $10(8)$ & $8(6)$ & $32(26)$ & $10(8)$ & $18(14)$ & $1(1)$ & $4(3)$ & $7(6)$ & $18(14)$ & $47(38)$ & $19(15)$ & $6(5)$ & $5(4)$ \\
\hline Endosteal spots & $87(70)$ & $5(4)$ & $0(0)$ & $1(1)$ & $0(0)$ & $4(3)$ & $77(62)$ & $54(43)$ & $2(2)$ & $0(0)$ & $0(0)$ & $0(0)$ & $0(0)$ & $12(10)$ \\
\hline Cortical hypertrophy & $1(1)$ & $6(5)$ & $1(1)$ & $0(0)$ & $3(2)$ & $1(1)$ & $0(0)$ & $0(0)$ & $1(1)$ & $0(0)$ & $0(0)$ & $0(0)$ & $1(1)$ & $0(0)$ \\
\hline
\end{tabular}

Table 7 Radiographic findings of the 99 non-revised sockets

\begin{tabular}{llll}
\hline Parameter & Zone 1 (\%) & Zone 2(\%) & Zone 3 (\%) \\
\hline Osteolysis/radiolucent lines & $2(1)$ & $10(10)$ & $1(1)$ \\
Radiodense lines & $8(8)$ & $0(0)$ & $2(2)$ \\
\hline
\end{tabular}

\section{Survivorship}

With the revision of the each component as the end point, the cumulative survival rate was $99 \%$ for the stem $(95 \%$ confidence interval, $98-100 \%), 99 \%$ for the metal shell $(97-100 \%)$, and $69 \%$ for the liner $(57-82.0 \%)$ at 10 years (Fig. 2).

\section{Discussion}

To our knowledge, this is the first report on the intermediate to long-term results of this specific intraoperatively machined second-generation femoral component which had been designed to address the specific problems of first-

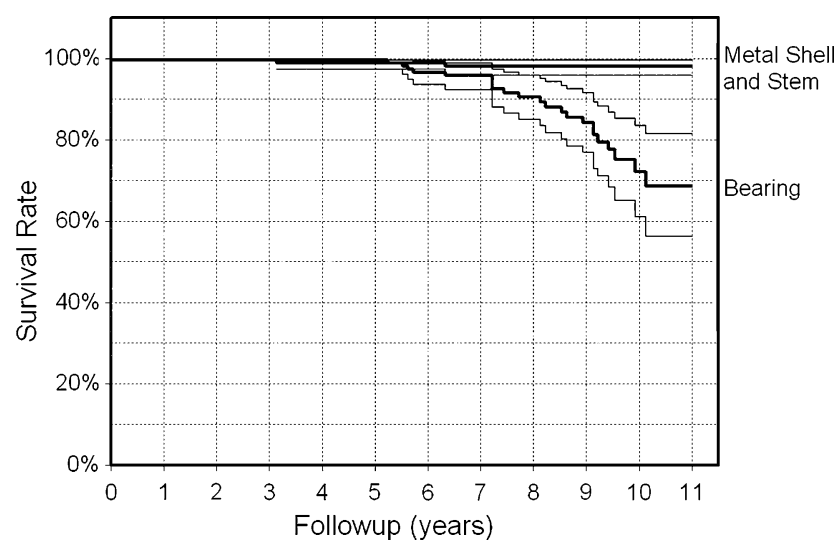

Fig. 2 A Kaplan-Meier survivorship analysis shows a 99\% rate of cup and stem survival, and a $69 \%$ rate for bearings with revision of the components as endpoint

generation cementless femoral implants. As we first hypothesized in the introduction, the cumulative 10-year survivorship of the investigated femoral component exceeds the results of first-generation stems and compares favorably to the survivorship of other second-generation stems (Table 9). In addition, our results support the second

Table 8 Factors associated with accelerated polyethylene liner wear and bearing exchanges

\begin{tabular}{llll}
\hline Parameter & $\begin{array}{l}\text { Bearing exchange } \\
(n=25)\end{array}$ & $\begin{array}{l}\text { No bearing exchange } \\
(n=117)\end{array}$ & $p$ value \\
\hline Age at surgery (years) & $44.4 \pm 8.0(30.4-61.6)$ & $48 \pm 10.6(25.1-70.1)$ & 0.121 \\
Hips with previous operation (\%) & $3(12)$ & $33(28)$ & 0.069 \\
Men patients $(\%)$ & $14(56)$ & $52(44)$ & 0.202 \\
Right side hips $(\%)$ & $15(60)$ & $59(50)$ & 0.258 \\
Abduction outliers $\left(<30^{\circ}\right.$ or $\left.>50^{\circ}\right)(\%)$ & $5(20)$ & $11(9)$ & 0.962 \\
Height $(\mathrm{cm})$ & $172 \pm 11(147-195)$ & $170 \pm 9(145-183)$ & 0.302 \\
Weight $(\mathrm{kg})$ & $85 \pm 27(51-134)$ & $28.1 \pm 5.0(18-38)$ & 0.413 \\
Body mass index $\left(\mathrm{kg} \mathrm{m}{ }^{-2}\right)$ & $28.1 \pm 7.0(18-41)$ & $16(16)$ & 0.994 \\
Stem malalignment $(\%$ varus $/$ valgus $)$ & $4(16)$ & $65(52)$ & 0.671 \\
Head diameter $\geq 28 \mathrm{~mm}(\%)$ & $20(80)$ & $63(54)$ & 0.018 \\
Cup diameter $\geq 54 \mathrm{~mm}(\%)$ & $15(60)$ & $17(15)$ & 0.368 \\
Hips with Hylamer PE $(\%)$ & $15(60)$ & $89(76)$ & $<0.0001$ \\
Hips with Enduron PE $(\%)$ & $10(40)$ & & $<.0001$ \\
\hline$P E$ polyethyl & & & \\
\hline
\end{tabular}

$P E$ polyethylene 


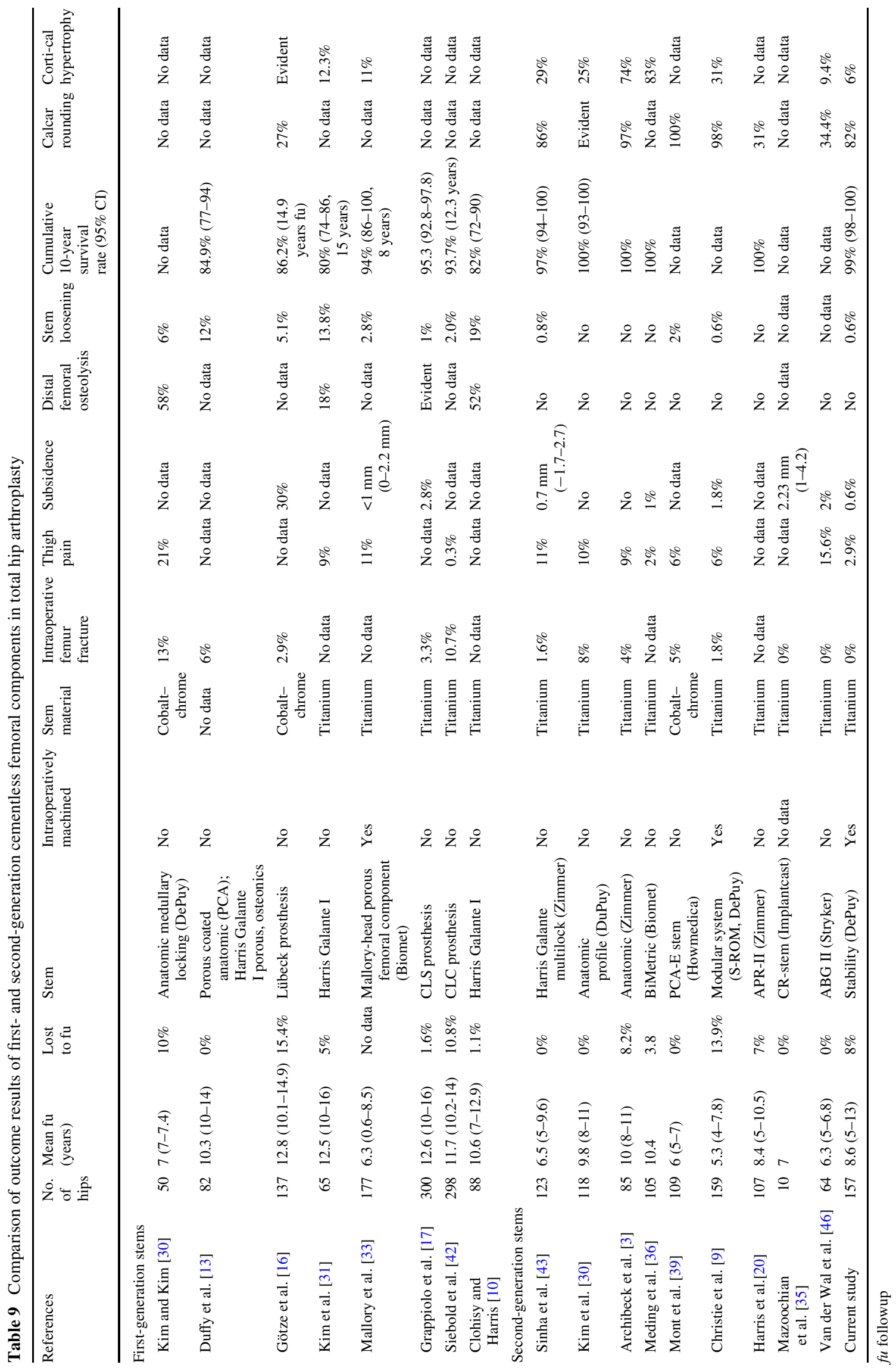


Fig. 3 The anteroposterior (a), lateral (b) and false profile (c) radiographs of 68-year-old patient 8 years after primary total hip prosthesis are shown. Although excessive polyethylene wear is visible, there is no evidence of osteolysis around the femoral or the acetabular component
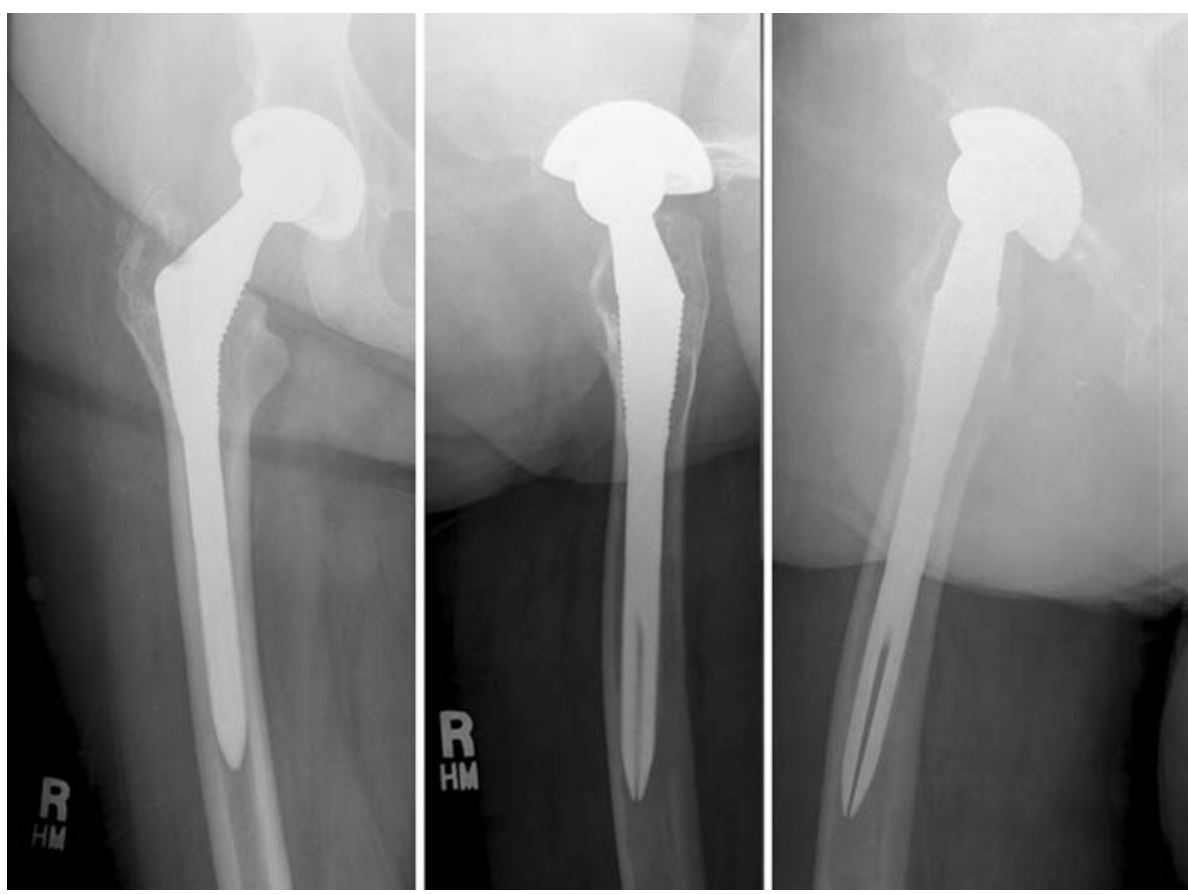

hypothesis that states that the specific features of the described stem leads to an absence of intraoperative femoral fractures, a lower incidence of activity-related thigh pain and femoral hypertrophy in comparison to other secondgeneration stems (Table 9). The disadvantages of this second-generation hip prosthesis are the necessity of the additional machining of the metaphysis in comparison to the broaching-only technique. This requires further technical skills for the surgeon that can lead to an increased operation time.

There are several limitations to our study. All the patients have been clinically evaluated by the operating surgeon. This might have positively biased the results. However, important parameters assessed in this study such as the severity and location of pain (particulary thigh pain) were obtained directly from the patients' questionnaires. These were completed in the absence of the evaluating surgeon; also, the radiographic analysis was done by another observer independent from the surgeon which should minimize bias. Another weakness of this study is the mixture of acetabular shells, polyethylene liners, and femoral heads. The original study protocol did not include particular exclusion criteria concerning this. Therefore, the investigated stem was combined with different types of polyethylene bearings and/or femoral head materials according to the latest technical advancements in this area. Unexpectedly, a high rate of bearing exchanges due to accelerate wear was found for Hylamer PE. One reason for this might be that those patients had a higher follow-up. Therefore, this finding is not particularly significant. Nevertheless, after recognition of this fact, the utilization of this type of PE was abandoned. From a theoretical point of view, the higher rate of wear could have negatively influenced the outcome of the investigated stem. However, no such difference could be observed in this series. The fact that this femoral component shows very reliable results despite being used with different bearing components rather reflects the quality of the investigated stem and does not jeopardize the results of our study. The stem survives with stability and can potentially serve as a barrier to $\mathrm{PE}$ debris and subsequent osteolysis (Fig. 3).

Our study documents that fluted titanium canal-filling femoral components routinely osseointegrate and can remain well fixed, even in a young patient population. Despite the significant wear of the retrieved polyethylene liners, none of the femoral components experienced distal osteolysis, suggesting that a circumferential seal between the implant and the femur might inhibit particulate debris migration (Table 6). This corresponds well with the longterm results of other proximally coated cementless stems (Table 9) and supports the conclusion that extensively coated femoral components are not necessary to achieve fixation or inhibit debris migration [3, 29, 33, 36, 40].

There are some technical differences between the investigated stem and the similar S-ROM design. The S-ROM stem is very smooth distally, polished really, and the tip of the stem is quite square, leading to more localized stress transfer at the tip. The evaluated stem has a chemically milled surface that facilitates osseointegration over a longer distance. Even if there is a proximal loading, there is osseointegration along the whole prosthesis. In addition, the stem tip of the investigated design is more bullet-shaped and this 
tapered design leads to a better distribution of the stress transfer at the tip of the prosthesis. Besides, the slightly different definition of osseous hypertrophy and the older patient population for the S-ROM stem [9], this might explain the higher incidence of cortical hypertrophy and calcar rounding for the S-ROM prosthesis [9] (Table 9). Other parameters, such as thigh pain, the rate of intraoperative femur fractures and subsidence did not differ substantially (Table 9).

The one stem and one cup failure were clearly due to technical reasons. The one stem that failed to osseointegrate was undersized. The one cup that loosened occurred in association with a failed locking mechanism, hardware migrating to the articulation, and associated accelerated wear.

Being aware that other factors can influence the longterm survivorship in THA, the femoral stem evaluated in this study appears to offer a balance of proximal stability and reduction in distal bending stiffness which can be illustrated radiographically. Proximal stability could be visualized by the increase in bone density in the proximal Gruen zones $(1,7,8$, or 14$)$ in $80 \%$ of all the cases as a sign for osseointegration. The distal radiodense lines around the tip of the prosthesis may be attributed to flexibility of the distal part of the prosthesis mainly due to the low modulus of elasticity of the titanium alloy and the coronal slot. Theoretically, a coronal slot should reduce the stem stiffness particularly with hip flexion which is confirmed by the fact that reactive radiodense lines were predominantly found on the lateral radiograph.

The 10-year cumulative survival rate compares favorably with the reports of so-called second-generation cementless femoral components in literature which rates from 97 to $100 \%$ [3, 29, 33, 36]. However, when comparing with these studies, the current study presents some additional findings. First, the absence of intraoperative femoral fractures in the present series is notable and may relate to careful preparation of the calcar region with the described intraoperative machining technique, eliminating the need for high-impact during preparation of the femur. In contrast, intraoperative femoral fractures associated with the broaching-only techniques were seen in up to $8 \%$ of recently published studies on cementless THA (Table 9). Second, the incidence of thigh pain of $2 \%$ is very low which may be explained by the combination of the slotted design in combination with titanium alloy. In other series with non-slotted stems, thigh pain was found up to $10 \%$ in cobalt-chromium and up to $11 \%$ in titanium stems [29, 40]. Third, cortical hypertrophy occurred only in three hips without previous femoral surgical intervention. This is considerably lower than the incidence of $29-83 \%$ of cortical hypertrophy in other studies $[33,40]$. The low incidence of cortical hypertrophy suggests that the stresses are transferred from the implant to the bone more proximally, eliminating high stress transfer in the diaphysis. This may be due to the metaphyseal geometry of the implant which also included horizontal steps which were designed to convert hip stresses to compressive stresses and confirms previous finite element analysis predictions [37].

In summary, uncemented intraoperatively machined fluted titanium canal-filling femoral components achieve reliable fixation. PE bearing wear and the need for bearing exchange was the only limitation of these constructs. Reduced wear with hard bearings or improved polyethylene bearings should be expected to further improve the results of total hip arthroplasty using these types of implants.

Acknowledgment One of the authors (MT) received personal funding from the Swiss National Science Foundation (SNSF).

\section{References}

1. Allen AM, Ward WG, Haygood TM (1995) Imaging of the total hip arthroplasty. J South Orthop Assoc 4:96-123

2. Anthony PP, Gie GA, Howie CR, Ling RS (1990) Localized endosteal bone lysis in relation to the femoral components of cemented total hip arthroplasties. J Bone Joint Surg Br 72:971-979

3. Archibeck MJ, Berger RA, Jacobs JJ, Quigley LR, Gitelis S, Rosenberg A, Galante JO (2001) Second-generation cementless total hip arthroplasty. J Bone Joint Surg Am 83:1666-1673

4. Barrack RL, Jasty M, Bragdon C, Haire T, Harris WH (1992) Thigh pain despite bone ingrowth into uncemented femoral stems. J Bone Joint Surg Br 74:507-510

5. Bobyn JD, Mortimer ES, Glassmann AH, Engh CA, Miller JE, Brooks CE (1992) Producing and avoiding stress shielding: Laboratory and clinical observations of noncemented total hip arthroplasty. Clin Orthop Relat Res 274:79-96

6. Bourne RB, Rorabeck CH, Ghazal ME, Lee MH (1994) Pain in the thigh following total hip replacement with a porous-coated anatomic prosthesis for osteoarthrosis. A five-year follow-up study. J Bone Joint Surg Am 76:1464-1470

7. Brooker AF, Bowerman JW, Robinson RA, Riley LH (1973) Ectopic ossification following total hip replacement. Incidence and a method of classification. J Bone Joint Surg Am 55:16291632

8. Callaghan JJ, Dysart SH, Savory CG (1988) The uncemented porous-coated anatomic total hip prosthesis. Two-year results of a prospective component. J Bone Joint Surg Am 70:337-346

9. Christie MJ, DeBoer DK, Trick LW, Brothers JC, Jones RE, Vise GT, Gruen TA (1999) Primary total hip arthroplasty with use of the modular S-ROM prosthesis. Four to seven-year clinical and radiographic results. J Bone Joint Surg Am 81:1707-1716

10. Clohisy JC, Harris WH (1999) The Harris-Galante uncemented femoral component in primary total hip replacement at 10 years. J Arthroplasty 14:915-917

11. D'Antonio JA, Capello WN, Jaffe WL (1992) Hydroxylapatitecoated hip implants. Clin Orthop Relat Res 285:102-115

12. DeLee JG, Charnley J (1976) Radiological demarcation of cemented sockets in total hip replacement. Clin Orthop Relat Res 121:20-32

13. Duffy GP, Berry DJ, Rowland C, Cabanela ME (2001) Primary uncemented total hip arthroplasty in patients $<40$ years old: 10 - to 14-year results using first-generation proximally porous-coated implants. J Arthroplasty 16:140-144 
14. Engh CA, Bobyn JD, Glassmann AH (1987) Porous-coated hip replacement: The factors governing bone ingrowth, stress shielding, and clinical results. J Bone Joint Surg Br 69:45-55

15. Fitzgerald RH Jr, Brindley GW, Kavanagh BF (1988) The uncemented total hip arthroplasty. Intraoperative femoral fractures. Clin Orthop Relat Res 235:61-66

16. Götze C, Tschugunow A, Götze HG, Bottner F, Potzl W, Gosheger $G$ (2006) Long-term results of the metal-cancellous cementless Lubeck total hip arthroplasty: a critical review at 12.8 years. Arch Orthop Trauma Surg 126:28-35

17. Grappiolo G, Blaha JD, Gruen TA, Burastero G, Spotorno L (2002) Primary total hip arthroplasty using a grit-blasted, press-fit femoral prosthesis. Long term results with survivorship analysis. Hip Intern 12:55-72

18. Gruen TA, McNeice GM, Amstutz HC (1979) "Modes of failure" of cemented stem-type femoral components: a radiographic analysis of loosening. Clin Orthop Relat Res 141:17-27

19. Hardidge AJ, Hooper J, McMahon S (2003) Current attitudes to total hip replacement in younger patients: a comparison of two nations. ANZ J Surg 73:280-283

20. Harris M, Dorr LD, Wan Z, Sirianni L, Boutary M (2005) Total hip arthroplasty with the APR stem and cup follow-up of a previous report. J Arthroplasty 20:828-831

21. Havelin LI, Espehaug B, Vollset SE, Engesaeter LB (1995) Early aseptic loosening of uncemented femoral components in primary total hip replacement. A review based on the Norwegian Arthroplasty Register. J Bone Joint Surg Br 77:11-17

22. Hedley AK, Gruen TA, Borden LS, Hungerford DS, Habermann E, Kenna RV (1987) Two-year follow-up of the PCA noncemented total hip replacement. Hip 225-250

23. Herrera A, Canales V, Anderson J, Garcia-Araujo C, MurciaMazon A, Tonino AJ (2004) Seven to 10 years followup of an anatomic hip prosthesis: an international study. Clin Orthop Relat Res 423:129-137

24. Huddlestone HD (1988) Femoral lysis after cemented hip arthroplasty. J Arthroplasty 3:285-297

25. Johnston RC, Fitzgerald RH, Harris WH, Poss R, Müller ME, Sledge CB (1990) Clinical and radiographic evaluation of total hip replacement. A standard system of terminology for reporting results. J Bone Joint Surg Am 72:161-168

26. Kalteis T, Handel M, Herold T, Perlick L, Paetzel C, Grifka J (2006) Position of the acetabular cup-accuracy of radiographic calculation compared to CT-based measurement. Eur J Radiol 58:294-300

27. Kaplan E, Meier P (1958) Nonparametric estimation from incomplete observations. J Am Statist Assn 53:457-481

28. Katz JN, Phillips CB, Poss R, Harrast JJ, Fossel AH, Liang MH, Sledge CB (1995) The validity and reliability of a total hip arthroplasty outcome evaluation questionnaire. J Bone Joint Surg Am 77:1528-1534

29. Kim YH, Kim VE (1993) Early migration of uncemented porous coated anatomic femoral component related to aseptic loosening. Clin Orthop Relat Res 295:146-155

30. Kim YH, Oh SH, Kim JS (2003) Primary total hip arthroplasty with a second-generation cementless total hip prosthesis in patients younger than fifty years of age. J Bone Joint Surg Am 85:109-114
31. Kim YG, Kim SY, Park BC, Kim PT, Ihn JC, Kim ID (2005) Uncemented Harris-Galante total hip arthroplasty in patients with osteonecrosis of the femoral head. A 10-16-year follow-up study. Acta Orthop 76:42-48

32. Kim YH, Kim VE (1994) Cementless porous-coated anatomic medullary locking total hip prostheses. J Arthroplasty 9:243-252

33. Mallory TH, Head WC, Lombardi AV, Emerson RH, Eberle RW, Mitchell MB (1996) Clinical and radiographic outcome of a cementless, titanium, plasma spray-coated total hip arthroplasty femoral component. Justification for continuance of use. J Arthroplasty 11:653-660

34. Martell JM, Pierson RH, Jacobs JJ, Rosenberg AG, Maley M, Galante JO (1993) Primary total hip reconstruction with a Titanium fiber-coated prosthesis inserted without cement. J Bone Joint Surg Am 75:554-571

35. Mazoochian F, Schrimpf FM, Kircher J, Mayer W, Hauptmann S, Fottner A, Müller PE, Pellengahr C, Jansson V (2007) Proximal loading of the femur leads to low subsidence rates: first clinical results of the CR-stem. Arch Orthop Trauma Surg 127:397-401

36. Meding JB, Keating EM, Ritter MA, Faris PM, Berend ME (2004) Minimum ten-year follow-up of a straight-stemmed, plasmasprayed, titanium-alloy, uncemented femoral component in primary total hip arthroplasty. J Bone Joint Surg Am 86:92-97

37. Menon DK, McCreath SW (1999) 5- to 8-year results of the Freeman press-fit hip arthroplasty. J Arthroplasty 14:581-588

38. Merle d'Aubigné R, Postel M (1954) Functional results of hip arthroplasty with acrylic prosthesis. J Bone Joint Surg Am 36:451-475

39. Mont MA, Yoon TR, Krackow KA, Hungerford DS (1999) Clinical experience with a proximally porous-coated second-generation cementless total hip prosthesis. Minimum 5-year follow-up. J Arthroplasty 14:930-939

40. Murphy SB (1995) Design rationale for intraoperatively machined uncemented femoral components in total hip replacement. Oper Techn Orthop 5:331-335

41. Scheerlinck T, Druyts P, Casteleyn PP (2004) The use of primary total hip arthroplasty in university hospitals of the European Union. Acta Orthop Belg 70:231-239

42. Siebold R, Scheller G, Schreiner U, Jani L (2001) Long-term results with the cement-free Spotorno CLS shaft. Orthopäde 30:317-322 (In German)

43. Sinha RK, Dungy DS, Yeon HB (2004) Primary total hip arthroplasty with a proximally porous-coated femoral stem. J Bone Joint Surg Am 86:1254-1261

44. Sutherland CJ, Wilde AH, Borden LS, Marks KE (1982) A ten-year follow-up of one hundred consecutive Müller curved-stem total hip replacement arthroplasties. J Bone Joint Surg Am 64:970-982

45. Tannast M, Langlotz U, Siebenrock KA, Wiese M, Bernsmann K, Langlotz F (2005) Anatomic referencing of cup orientation in total hip arthroplasty. Clin Orthop Relat Res 436:144-150

46. Van der Wal BC, de Kramer BJ, Grimm B, Vencken W, Heyligers IC, Tonino AJ (2008) Femoral fit in ABG-II hip stems, influence on clinical outcome and bone remodeling: a radiographic study. Arch Orthop Trauma Surg 128:1065-1072

47. Xenos JS, Hopkinson WJ, Callaghan JJ, Heekin RD, Savory CG (1995) Osteolysis around an uncemented cobalt chrome total hip arthroplasty. Clin Orthop Relat Res 317:29 